\title{
Konik Işınlı Bilgisayarlı Tomografi Görüntülerinde Kök Kanal Dolgulu Dişlerde Oluşan Artefaktların Değerlendirilmesi
}

Ayşe Aydoğmuş Erik(0000-0001-8968-5955) ${ }^{\alpha}$, Derya Yıldırım(0000-0003-3125-1358) ${ }^{\beta}$, Cevat Emre Erik(0000-0003-2706-1914) ${ }^{\alpha}$

Selcuk Dent J, 2021; 8: 796-801 (Doi: 10.15311/selcukdentj.997425)

Başvuru Tarihi: 19 Eylül 2021 öz

\section{Konik Işınlı Bilgisayarlı Tomografi Görüntülerinde Kök Kanal Dolgulu Dişlerde Oluşan Artefaktların Değerlendirilmesi}

Amaç: Bu çalışmanın amacı, kök kanal dolgulu dişlerin KIBT görüntülerinde oluşan artefakt tiplerini belirlemek oluşan artefaktların farklı kök kanal dolgu patları ve farklı görüntüleme parametreleriyle ilişkisini değerlendirmektir.

Gereç ve Yöntemler: Çalışmada AH Plus $\AA, A H 26 \AA$, Sealapex $\AA$, Sealite Regular $\AA$, 2Seal $\AA$, Endofill $\AA$, MTA Fillapex ${ }^{\circledR}$, Well Root $S T \AA$ kök kanal dolgu patları ve guta-perka kullanılarak 63 çekilmiş insan kesici dişine kanal dolgusu yapıldı. Tüm dișler $0.4 \mathrm{~mm}$ voksel boyutunda 200 genișlik ve 60 $\mathrm{mm}$ yükseklikte FOV ile $0.2 \mathrm{~mm}$ voksel boyutunda $40 \mathrm{~mm}$ genişlik ve $50 \mathrm{~mm}$ yükseklikte FOV'da olmak üzere iki farklı parametrede, KIBT (Planmeca ProMax 3D Mid ${ }^{\circledR}$ ) ile görüntülendi. Görüntülerde streaking ve cupping artefakt tipleri belirlendi.

Bulgular: Apikal kısımda artefakt görülme frekansı ve yüzde dağılımları koronal bölgeye göre anlamlı ölçüde azdı $(p<0.01)$. Küçük FOV ve voksel parametresiyle koronal bölgede streaking artefaktı oluşumunda anlamlı farklılık gözlenmezken $(p=0.15)$, apikal bölgede streaking artefaktı azaldı $(p=0.006)$, cupping artefaktı ise koronal $(p=0.004)$ ve apikalde $(p=0.003)$ arttı.

Sonuç: Farklı kanal patlarıyla ilişkili olarak KIBT görüntülerinde streaking ve cupping artefaktları, koronal kısımda daha fazla olmak üzere gözlenmektedir. Görüntülemede streaking artefaktının azaltılması için küçük FOV ve voksel boyutu tercih edilmelidir.

\section{ANAHTAR KELIMELER}

Artefakt, Konik ışınlı bilgisayarlı tomografi, Kök kanal dolgu patı

Endodontik teşhis ve tedavi planlamasında radyografik muayene önemli bir yer tutar. Konik ışınlı bilgisayarlı tomografi (KIBT), endodontik patolojilerin teşhisinde, kanal yapılarının incelenmesinde, kök kırıklarının ve travmaların değerlendirilmesinde, eksternal ve internal kök rezorpsiyonlarının analizinde, endodontik cerrahi öncesinde ve endodontik implant planlamasında kullanılır. ${ }^{1}$

KIBT görüntüleme tedavideki birçok avantajı ile birlikte azaltılmış radyasyon dozları ve daha iyi çözünürlüklerde yeni tarayıcıların kullanımıyla endodontik tedavi planlaması ve değerlendirmesi için

\section{ABSTRACT}

Evaluation of Artifacts in Root Canal Filled Teeth on ConeBeam Computed Tomography Images

Background: The aim of this study was to determine the types of artifacts on CBCT images of endodontically treated roots related with several root canal sealers and different imaging parameters.

Methods: In this study, root canal treatment was performed on 63 extracted human incisors by using AH Plus $\AA, A H 26 \AA$, Sealapex $\AA$, Sealite $\operatorname{Regular} \AA$, 2Seal $\AA$, Endofill ${ }^{\circledR}, \quad$ MTA Fillapex ${ }^{\circledR}$, Well Root $S T \AA$ sealers and gutta-percha cone. All teeth were scanned using CBCT (Planmeca ProMax 3D Mid $($ ) in two different parameters; $0.4 \mathrm{~mm}$ voxel size, $200 \mathrm{~mm}$ width and $60 \mathrm{~mm}$ height FOV, and $0.2 \mathrm{~mm}$ voxel size, $40 \mathrm{~mm}$ width and 50 $\mathrm{mm}$ height FOV. Streaking ve cupping artifacts were evaluated on CBCT images.

Results: The frequency and percentage of artifacts on the apical region was significantly less than in the coronal region $(p<0.01)$. There was no significant difference $(p=0.15)$ in the formation of streaking artifacts between small FOV - voxel and large FOVvoxel parameters on the coronal region while it was significantly decrease $(p=0.006)$ with small FOV-voxel parameters on the apical region. Cupping artifact was significantly increase on coronal $(p=0.004)$ and apical $(p=0.003)$ region in small FOV and voxel parameters.

Conclusion: Streaking and cupping artifact releated with different root canal sealers were most significantly occur on coronal region on CBCT images. The use of smaller FOV and voxel size should be preferred to reduce streaking artifacts.

\section{KEYWORDS}

Artifact, Cone beam computed tomography, Root canal filling sealers

tercih edilmektedir. Bununla beraber endodontik vakalar kendine özgü olarak değerlendirilmelidir ve KIBT kullanımı, endodontik problemlerin uygun tedavisini sağlamak için geleneksel görüntüleme yöntemlerinden yeterli bilgi sağlanamadığı durumlar için düşünülmelidir. ${ }^{2}$

Klinisyenin kök kanal dolgusu ve çevresindeki anatomik yapıları değerlendirmede net bir ayrım yapabilmesi için kök kanal patının yeterli radyopasitede olması istenir. ${ }^{3}$ Kök kanal dolgu maddelerinin içeriğinde bulunması istenen radyopasite veren maddeler radyograflarda klinisyenlere teşhiste kolaylık sağlarken KIBT

\footnotetext{
${ }^{\alpha}$ Özel Akademi Ağız ve Diş Sağlığı Polikliniği Antalya, Türkiye

$\beta$ Süleyman Demirel Üniversitesi Diş Hekimliği Fakültesi Ağız, Diş Ve Çene Radyolojisi AD, Isparta, Türkiye
} 
görüntülerinde artefakt oluşturarak teşhisin zorlaşmasına neden olabilmektedir. Artefaktlar, bir radyografta incelenen bölgenin anatomik yapısı ile ilgili olmayan, radyografi işlemi sırasında bir hata sonucu oluşan istenmeyen görüntü bozukluklarıdır. ${ }^{1,4}$ KIBT'de görüntü kalitesini bozan temel faktör görüntü artefaktıdır.

Endodontik tedaviler sırasında kök kanal morfolojileri ve dişlerin çevre dokularla komşuluğunun üç boyutlu olarak incelenerek bu yapılara ait patolojilerin detaylı olarak belirlenmesi oldukça önemlidir. Avantajları göz önünde bulunduruldugunda KIBT'nin endodonti alanında yaygın olarak kullanılması gereken bir teşhis aracı oldugu çeșitli çalıșmalarda rapor edilmiștir. ${ }^{5}$

Konvansiyonel röntgen filmi ve dijital sensörlerle elde edilen periapikal radyogram ve imajlarda üç boyutlu yapıların iki boyutlu görüntüsü elde edilir. Bu yöntemlerde diğer yapıların görüntü üzerine süperpozisyonu söz konusu olabilmektedir. Kesit görüntülerde bu sorun ortadan kalkar. ${ }^{1}$

KIBT'nin doldurulmuş kök kanallarında perforasyon tespitinde, kök kanal tedavisi ve post uygulanması sonrasında oluşan kırıkların ve kırık aletlerin tespitinde hassasiyetinin azaldığı göz önünde bulundurulmalıdır. ${ }^{6}$ Bunun nedeni kök kanal tedavili dişlerde; kanal dolgu patlarının ve kırık kanal aletlerinin, KIBT görüntülerinde ışın sertleşmesi olarak adlandırılan, "cupping artefaktı" olarak bilinen, farklı absorpsiyonların sonucu metalik yapıların görüntüsündeki bozulmalar ve "streaking" olarak bilinen, iki dens cisim arasında görülen çizgiler ve koyu bantlardır. ${ }^{1,7-9}$

$\mathrm{Bu}$ çalışmada, kök kanal dolgulu dişlerin KIBT görüntülerinde oluşan artefakt tiplerini belirlemek, oluşan artefaktların farklı kök kanal dolgu patları ve görüntüleme parametreleriyle ilişkisini değerlendirmek amaçlanmıştır.

\section{GEREÇ VE YÖNTEMLER}

Bu çalışma Süleyman Demirel Üniversitesi Diş Hekimliği Fakültesi Ağız, Diş ve Çene Radyolojisi Kliniğinde, Süleyman Demirel Üniversitesi Tıp Fakültesi Etik Kurulu'nun 27/05/2015 tarih 133 sayılı (No: 72867572050-1705) izni alınarak gerçekleştirildi. Araştırmada çekilmiş insan kesici dişlerine kanal tedavisi uygulandıktan sonra alınan KIBT görüntülerinde, farklı kök kanal dolgu patlarının karşılaştırılarak kök kanal dolgu patlarıyla ilişkili oluşan artefaktların tipleri belirlendi ve değerlendirildi.

Yaşları 18 ile 45 yaş arası değişen hastalardan periodontal ve ortodontik sebeplerle çekilmiş, 63 tane tek köklü diş periapikal radyografi çekilerek değerlendirildi. Apikal forameni açık olmayan, mine ve kök kırığı/ çatlağı bulunmayan, dentinde herhangi bir çürüğü olmayan, tek köklü ve tek kanallı, birbirine yakın kök boyuna ve kalınlığına sahip daimi kesici dişleri seçildi.
Altmış üç çekilmiş tek köklü kesici dişe rutin kök kanal tedavisi uygulandı. Kök uzunluğu 14 mm olacak şekilde dişlerin kronları ve gerekliyse kök kısımları kesilerek çıkarıldı.

AH Plus ${ }^{\circledR}$, AH $26 \AA$, Sealapex $\AA$, Sealite Regular ${ }^{\circledR}$, 2Seal ${ }^{\circledR}$, Endofill ${ }^{\circledR}$, MTA Fillapex ${ }^{\circledR}$, Well Root ST ${ }^{\circledR}$ kök kanal dolgu patları ve guta perka kullanılarak her bir grupta 7 diş olmak üzere toplamda 63 çekilmiş kesici dişe kök kanal dolgusu yapıldı.

Her bir diş kökü kuru mandibula üzerine yerleştirildi ve mum yardımıyla sabitlendi. Kuru mandibula 15 × $15 \times 15$ $\mathrm{cm}$ boyunda, $2 \mathrm{~mm}$ kalınlıkta şeffaf plastik kutuya silikon ölçü maddesi yardımıyla midsagital sagital düzlem ile çakışacak şekilde sabitlendi. Yumuşak doku simülasyonu için plastik kutu içerisine su doldurulup kuru mandibulanın etrafında $20 \mathrm{~mm}$ su kalınlığı elde edilerek ortalama bir yetişkin insan yumuşak doku kalınlığı olan su fontomu oluşturuldu. Fantom çene tutucu aparat kullanılarak pozisyonlandırıldı. Midsagital düzlem yer düzlemiyle dik, mandibula tabanı yere paralel olarak konumlandırıldı.

Sekiz ayrı kök kanal dolgu patı ve guta-perka ile sadece guta-perka (kontrol) kullanılarak oluşturulan 9 grup için, her grupta 7 dişe kök kanal tedavisi tamamlanan toplam 63 diş kök örneğine 2 ayrı FOV (Görüntü alanı (Feild of view)) ve voksel parametresinde KIBT (Planmeca ProMax 3D Mid, Helsinki, Finland, 2011) taraması yapıldı.

Her bir dişin KIBT görüntülenmesinde flat panel dedektör sistemi olan KIBT cihazında tetkik parametreleri $90 \mathrm{kVp}, 10 \mathrm{~mA}$ olarak ayarlandı. KIBT taramalarında çözünürlük ayarları değiştirilmedi.

\section{Tarama 1}

$0.4 \mathrm{~mm}$ voksel boyutu, $200 \times 60 \mathrm{~mm}$ FOV, $13.6 \mathrm{sn}$

\section{Tarama 2}

\section{$0.2 \mathrm{~mm}$ voksel boyutu, 40 X $50 \mathrm{~mm}$ FOV, $12.1 \mathrm{sn}$}

Toplamda 126 ayrı KIBT görüntüsü değerlendirmeye alındı. Alınan KIBT görüntüleri 21.5“ HP s2231a LCD monitörde (HP, Houston, ABD), 1920 X 1080 piksel ekran çözünürlüğünde, 32 bit renk derinliğinde değerlendirildi. Görüntüler Romexis yazılımında (Planmeca Oy, Helsinki, Finland) incelendi. Tüm KIBT görüntülerinde aksiyel kesitte oluşan artefaktlar incelendi. Görüntülerde diş kökü apeksten itibaren 7 $\mathrm{mm}$ ölçülerek apikal ve koronal olmak üzere iki eşit bölümde değerlendirildi. Kökün apikal ve koronal bölgelerinde oluşan "cupping" ve "streaking" artefaktları $0.02 \mathrm{~mm}$ kesit kalınlığında incelendi. Gözlemlenen artefaktlar "var" ya da "yok" olarak kaydedildi. 2 hafta sonra, görüntülerin \% 20'sinde inceleme tekrarlanarak gözlemci içi uyuma bakıldı.

\section{İstatistiksel analiz}

$\mathrm{Bu}$ çalışmada verilerin istatsitiksel analizi için SPSS 
(Version 18.0, Chicago, USA) programı kullanıldı. Artefakt tiplerinin belirlenmesinde gözlemci içi uyuma bakmak için nonparametrik testlerden olan Cohen'nin kappa ölçüsü hesaplandı. Kök kanal dolgu patlarının oluşturduğu artefakt tipleri koranal ve apikal bölgede Tukey testi kullanılarak değerlendirildi. Kök kanal dolgu patlarının oluşturduğu artefakt tiplerinin frekans ve yüzde dağılımları çapraz tablo (crosstab) yöntemi ile analiz edildi. Koronal ve apikal bölgede göre artefakt tipleri $x^{2}$ testi kullanılarak değerlendirildi. Koronal ve apikal bölgede oluşan artefakt tiplerinin frekans ve yüzde dağılınları çapraz tablo (crosstab) yöntemi ile analiz edildi. Kök kanal dolgu patlarının oluşturduğu artefakt tipleri FOV ve voksel boyutuna göre Tukey testi kullanılarak değerlendirildi. FOV ve voksel boyutuna göre oluşan artefakt tiplerinin frekans ve yüzde dağılımları çapraz tablo (crosstab) yöntemi ile analiz edildi.

\section{BULGULAR}

Kök kanal dolgu patlarının oluşturduğu artefakt tipleri bir gözlemci (AAE) tarafından belirlendi (Resim 1).

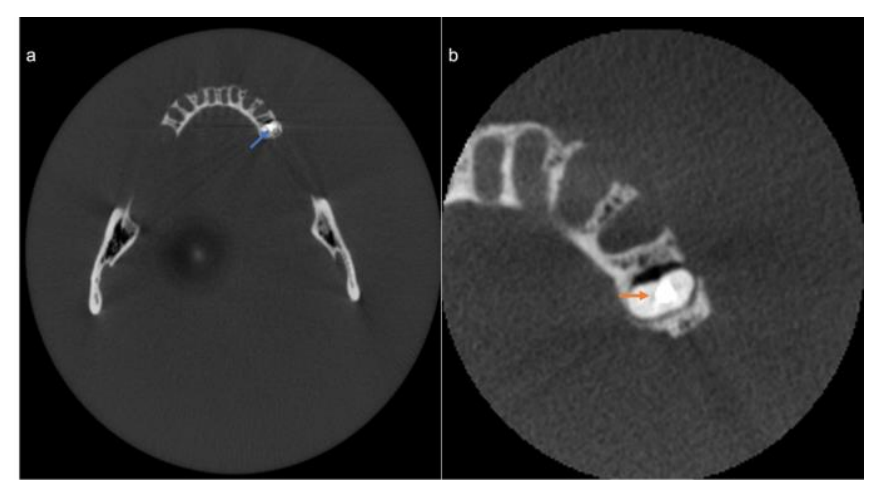

Resim 1

a) $200 \mathrm{X} 60 \mathrm{~mm}$ FOV 'da kök kanal dolgu materyali etrafinda oluşan streaking artefaktı (mavi ok), b) 40 X 50 mm FOV'da kök kanal dolgu materyali etrafinda oluşan cupping artefaktı (turuncu ok)

Gözlemci içi uyumu değerlendirmek için 24 KIBT görüntüsünde iki kez artefakt tipi belirlendi. Artefakt tiplerinin belirlenmesi için, nonparametrik testlerden olan Cohen'in kappa test istatistiği ile gözlemci içi uyum ölçüldü $(k=0.84)$. Bu çalışmada artefakt tipinin belirlenmesinde mükemmel derece uyuşma olduğu belirlendi.

Her bir kök kanal dolgu patı için 14 ayrı KIBT görüntüsü değerlendirildi. Kök kanal dolgu patlarının oluşturduğu artefakt tiplerinin frekans ve yüzde dağılımları çapraz tablo (crosstab) yöntemi ile analiz edildi (Tablo 1).

Toplam 126 KIBT görüntüsünden elde edilen veriler, kök kanal patlarının oluşturduğu artefakt tipleri bakımından koronal ve apikal bölgede Tukey testi kullanılarak değerlendirildi. Koronal bölgede artefakt tipleri bakımından kök kanal dolgu patları arasında fark görülmedi $(p>0.05)$.

\section{Tablo 1.}

\section{Artefakt tiplerine göre koronal ve apikalde oluşan frekans ve yüzde dağılımları çapraz tablolar (crosstabs) yöntemi ile elde edildi.}

\begin{tabular}{|lccc|ccc|}
\hline \multicolumn{5}{|c|}{ Koronal $(\mathbf{n = 1 4 )}$} & \multicolumn{2}{c|}{ Apikal $(\mathbf{n = 1 4 )}$} \\
\hline $\begin{array}{l}\text { Kök } \\
\text { kanal } \\
\text { dolgu } \\
\text { materyali }\end{array}$ & $\begin{array}{c}\text { streaking } \\
\mathbf{n ( \% )}\end{array}$ & $\begin{array}{c}\text { cupping } \\
\mathbf{n}(\%)\end{array}$ & $\begin{array}{c}\text { streaking } \\
\text { cupping }\end{array}$ & streaking & cupping & $\begin{array}{c}\text { streaking+ } \\
\text { cupping }\end{array}$ \\
\hline AH Plus & $14(100)$ & $11(78.57)$ & $11(78.57)$ & $14(100)$ & $10(71.43)$ & $10(71.43)$ \\
\hline Sealapex & $14(100)$ & $7(50)$ & $7(50)$ & $13(92.86)$ & $6(42.86)$ & $6(42.86)$ \\
\hline 2 Seal & $14(100)$ & $9(64.29)$ & $9(64.29)$ & $13(92.86)$ & $7(50)$ & $6(42.86)$ \\
\hline AH 26 & $13(92.86)$ & $7(50)$ & $7(50)$ & $9(64.29)$ & $6(42.86)$ & $3(21.43)$ \\
\hline $\begin{array}{l}\text { Sealite } \\
\text { Regular }\end{array}$ & $14(100)$ & $7(50)$ & $7(50)$ & $14(100)$ & $6(42.86)$ & $6(42.86)$ \\
\hline Endofill & $14(100)$ & $8(57.14)$ & $8(57.14)$ & $14(100)$ & $7(50)$ & $7(50)$ \\
\hline $\begin{array}{l}\text { MTA } \\
\text { Fillapex }\end{array}$ & $13(92.86)$ & $7(50)$ & $6(42.86)$ & $13(92.86)$ & $7(50)$ & $6(42.86)$ \\
\hline $\begin{array}{l}\text { Well Root } \\
\text { ST }\end{array}$ & $14(100)$ & $8(57.14)$ & $8(57.14)$ & $13(92.86)$ & $5(35.71)$ & $5(35.71)$ \\
\hline $\begin{array}{l}\text { Guta } \\
\text { perka }\end{array}$ & $14(100)$ & $7(50)$ & $7(50)$ & $12(85.71)$ & $7(50)$ & $5(35.71)$ \\
\hline
\end{tabular}

Kök kanal dolgu patlarının oluşturduğu artefakt tipleri apikal ve koronal bölgeye göre frekans ve yüzde dağılımları çapraz tablo (crosstab) yöntemiyle analiz edildi. Kök kanal dolgu patlarının oluşturduğu artefakt tipleri analiz edildiğinde koronal bölgede \% 98.41 oranında "streaking" artefaktı, \% 57.14 oranında "cupping" artefaktı, \% 55.6 oranında her iki artefakt da birlikte gözlendi. Apikal bölgede \% 91.27 oranında "streaking" artefakı, \% 48.41 oranında "cupping" artefaktı, \% 42.86 oranında her iki artefakt da birlikte gözlendi.

Artefakt tipleri koronal ve apikal bölgeye göre $x^{2}$ testi ile analiz edildi. Koronal ve apikal bölgede artefakt tipleri değerlendirildiğinde artefakt tiplerinin arasında istatistiksel olarak fark görüldü $(p<0.01)$ (Tablo 2).

Tablo 2.

Koronal ve apikal bölgede artefakt tiplerine göre oluşan artefakt sayıları ve yüzdeleri $x^{2}$ testi ile analiz edilerek verilmiştir.

\begin{tabular}{|lccc|} 
& streaking & cupping & streaking+ cupping \\
\hline Koronal $(\mathrm{n}=126)$ & $\mathbf{n}(\%)$ & $\mathbf{n}(\%)$ & $\mathbf{n}(\%)$ \\
\hline Apikal $(\mathrm{n}=126)$ & $124(98.41)$ & $72(57.14)$ & $70(55.6)$ \\
\hline $\mathrm{P}$ & $115(91.27)$ & $61(48.41)$ & $54(42.86)$ \\
\hline${ }^{*} p<0,01$ & $0,007^{*}$ & $0,006^{*}$ & $0,003^{\star}$ \\
\hline
\end{tabular}

Kök kanal dolgu patlarının oluşturduğu artefakt tiplerinin FOV'a göre karşılaştırıması tek yönlü ANOVA testi ile analiz edildi. Koronal bölgede büyük FOV ve küçük FOV arasında streaking artefaktı bakımından istatistiksel olarak fark olamamasına rağmen ( $p>0.05)$, küçük FOV ve voksel boyutunda alınan görüntülerde "cupping" artefaktı istatistiksel olarak anlamlı derecede fazla görüldü ( $p=0.004)$ (Tablo3). 
Apikal bölgede küçük FOV ve voksel boyutunda alınan görüntülerde "streaking" artefaktı istatistiksel olarak daha az görülürken $(p=0.006)$, cupping artefaktı istatistiksel olarak daha fazla görüldü $(p=0.003)$ (Tablo 3).

Kök kanal dolgu patlarının oluşturduğu artefakt tipleri FOV'a göre frekans ve yüzde dağılımları çapraz tablo (crosstab) yöntemi ile analiz edildi. Kök kanal dolgu patlarının oluşturduğu artefakt tipleri analiz edildiğinde büyük FOV ve voksel boyutunda alınan görüntülerde koronal bölgede "streaking" artefaktı \% 100 oranında, "cupping" artefaktı \% 14.29 oranında her iki artefakt ise \% 14.29 oranında gözlendi (Tablo 3).

Büyük FOV ve voksel boyutunda alınan görüntülerde apikal bölgede streaking artefaktı \% 100 oranında, \% 6.3 oranında cupping artefaktı, her iki artefakt ise \% 6.3 oranında gözlendi (Tablo 3).

Küçük FOV'da koronal bölgede \% 96.82 oranında streaking artefaktı, \% 100 oranında cupping artefaktı, \% 96.82 oranında ise her iki artefakt birlikte gözlenirken, apikal bölgede \% 82.54 oranında streaking artefaktı, \% 90.48 oranında cupping, \% 79.37 oranında ise her iki artefakt birlikte gözlendi (Tablo 3 ).

Tablo 3.

FOV ve voksel boyutuna göre oluşan artefakt tiplerinin frekans ve yüzde dağılımları çapraz tablolar (crosstabs) yöntemi ile analiz edildi.

\begin{tabular}{|lcccccc|} 
& koronal & & $\mathbf{p}$ & apikal & & p \\
\hline & $\begin{array}{c}\text { Büyük } \\
\text { FOV } \\
(\mathbf{n = 6 3 )}\end{array}$ & $\begin{array}{c}\text { Küçük } \\
\text { FOV } \\
(\mathbf{n}=63)\end{array}$ & & $\begin{array}{c}\text { Büyük } \\
\text { FOV } \\
(\mathbf{n = 6 3 )}\end{array}$ & $\begin{array}{c}\text { Küçük } \\
\text { FOV } \\
(\mathbf{n}=63)\end{array}$ & \\
\hline $\begin{array}{l}\text { streaking } \\
\mathrm{n}(\%)\end{array}$ & $63(100)$ & $61(96.82)$ & 0.15 & $63(100)$ & $52(82.54)$ & $0.006^{*}$ \\
\hline $\begin{array}{l}\text { cupping } \\
\mathrm{n}(\%)\end{array}$ & $9(14.29)$ & $63(100)$ & $0.004^{*}$ & $4(6.3)$ & $57(90.48)$ & $0.003^{*}$ \\
\hline $\begin{array}{l}\text { streaking+cupping } \\
\mathrm{n}(\%)\end{array}$ & $9(14.29)$ & $61(96.82)$ & $0.007^{*}$ & $4(6.3)$ & $50(79.37)$ & $0.005^{*}$ \\
\hline${ }^{*} p<0,01$ & & & & & & \\
\hline
\end{tabular}

\section{TARTIŞMA}

Radyografik görüntülerde artefaktlar düzensiz gri seviyesi ve bozulmalar oluşturarak görüntü kalitesini olumsuz yönde etkiler. Klinisyenin teşhiste bazı bulguları kaçırmasına ya da yanlış teşhis koymasına neden olabilir. KIBT görüntülerinde oluşan artefaktların görüntü kalitesi üzerine etkileri günümüzde oldukça ilgi çeken ve üzerinde araştırmaların artarak devam ettiği konular arasındadır. Artefaktlar hasta, fiziki ortam, cihaz ve teknik faktörler kaynaklı olabilir. KIBT görüntülerinde oluşturduğu artefaklar açısından kök kanal dolgu maddeleri ${ }^{10-12}$, kök kanal dolgu patları ${ }^{13,14}$, kanal içi post materyalleri ${ }^{15,16}$, dental implantlar ${ }^{17,18,19-21}$, ortodontik braketler ${ }^{22}$, dental amalgamlar restorasyonlar $^{23}$ yapılan çeşitli çalışmalarda incelenmiştir.

KIBT görüntülerinde ışın sertleşmesi artefaktlarının olması, dental yapıların görülmesini güçleştirdiği için kök rezorpsiyonlarında, artı kanalların varlığında ve özellikle vertikal kök kırığı vakalarında endodontik teşhisi zorlaştırabilir. Işın sertleşmesi artefaktlarının oluşturduğu hipodens çizgiler ile kök kırığının radyografik görünümünün benzer olması, kök kırıklarının yanlış teşhisine ve bazı durumlarda gereksiz diş çekimlerine neden olabilir. ${ }^{10,24}$ Neves ve ark. ${ }^{10}$ KIBT görüntülerinde vertikal kök kırığının teşhisini değerlendirmişler ve kanal içi materyallerin varlığında kök kırığı teşhisinin zorlaştırdığını bildirmişlerdir. Pinto ve ark. ${ }^{24}$ yaptıkları çalışmada KIBT görüntülerinde kök kırığı teşhisinde ışınlama parametrelerinin ve kanal içi materyallerin etkisini araştırmışlardır. Kök kırığı teşhisine, ışınlama parametrelerinin etkisi olmadığını ancak kanal içi materyallerin oluşturduğu artefaktın etkili olduğunu belirtmişlerdir. Bu çalışmada, KIBT görüntülemesinde, endodontik teşhisi güçleştiren kök kanal dolgu patlarının oluşturduğu artefaktları değerlendirmek amacıyla farklı kök kanal dolgu patlarıyla ilişkili artefakt tipleri değerlendirildi. KIBT görüntülemesinde kanal patlarıyla ilişkili oluşan artefaktlara FOV ve voksel boyutunun etkisini incelemek amacıyla bu çalışma planlandı.

Literatürde kök kanal dolgu patlarının KIBT görüntülerinde oluşturduğu artefaktlarının değerlendirildiği çalışmalar mevcuttur. ${ }^{13,25,26}$ BritoJunior ve $\operatorname{ark}^{13}$. tarafından yapılan bu çalışmada Endofill, Sealer ${ }^{26}$, Fillapex ve AH Plus kök kanal dolgu patlarını kullanılmıştır. KIBT görüntülerinde iki farklı voksel boyutunda yapılan taramalarda oluşan streaking artefaktlarını var/yok olarak değerlendirmişlerdir ${ }^{13}$. Brito-Junior ve ark. ${ }^{13}$ tarafından yapılan çalışmada kullanılan materyaller olan AH Plus, Endofill, MTA Fillapex ve guta perka bu çalışmada da değerlendirilmiştir. Bu çalışmanın sonucunda da BritoJunior ve ark. ${ }^{13}$ tarafından elde edilen bulguları destekler şekilde streaking artefaktı FOV ve voksel boyutunun küçülmesiyle azalmış ve apikal kısımda bu azalma istatistiksel olarak anlamlı bulunmuştur.

Apikal kısımda AH 26 kök kanal dolgu patının oluşturduğu streaking artefaktı sayısı, AH Plus, Sealite Regular, Endofill kök kanal dolgu patlarının oluşturduğu streaking artefaktı sayısından istatistiksel olarak anlamlı ölçüde daha az görülmüştür $(p<0.05)$. Apikal kısımda cupping arefakt tipi bakımından tüm kök kanal dolgu patları arasında istatistiksel farklılık görülmemiştir ( $p>0.05)$. Görduysus ve ark. ${ }^{27}$ tarafından yapılan çalışmaya göre $\mathrm{AH} 26$ kök kanal patının radyoopasitesi, AH Plus, Sealite ve Endofill kök kanal patının ve guta perka radyoopasitesinden düşüktür. ${ }^{27}$ $\mathrm{AH} 26$ materyaliyle ilişkili olarak streaking artefaktının anlamlı şekilde az görülmesinin, $\mathrm{AH} 26$ materyalinin daha düşük radyopasite göstermesiyle ilişkili olabileceği düşünülmüştür.

Çalışmamızda literatürden farklı olarak, kökler apikal ve koronal olarak iki kısma ayrılarak incelenmiş ve cupping artefaktı da değerlendirilmiştir. Oluşan artefakt 
sayısı bakımından FOV ve voksel küçüldükçe, apikal ve koronalde oluşan cupping artefaktı sayısı anlamlı şekilde artmış, streaking artefaktı sayısı ise apikalde anlamlı şekilde azalmıştır (Tablo 3). FOV ve vokselin azalması neticesinde görüntü çözünürlüğü artmaktadır. ${ }^{28-31}$ Çalışmamızda FOV ve vokselin azalması ile streaking artefaktı azalmış, cupping artefaktı ise artmışıı. Bu durumun, streaking artefaktının görüntüde azalması ve cupping artefaktının daha görünür hale gelmesi ile ortaya çıkmış olabileceği düşünülmektedir. Ayrıca, diş kökü ve kök kanalının apikale doğru azalan konik formdaki anatomisi nedeniyle kökün koronal kısmında bulunan kanal dolgu maddesinin, apikalden daha çok olması durumu nedeniyle de artefaktların koronal kök kısmında daha çok görülmüş olabileceğini düşünmekteyiz.

Apikal kısımda gözlenen streaking artefaktı sayısı bakımından AH 26 kök kanal patı AH Plus, Sealite Regular ve Endofill kök kanal patlarının oluşturduğu artefakt sayısından istatistiksel olarak anlamlı derecede azdır $(p=0.02)$. Apikal bölgede gözlenen diğer artefakt tipleri açısından hiçbir kök kanal patı arasında fark görülmedi $(p>0.05)$.

FOV ve vokselin küçülmesiyle koronalde streaking artefaktı oluşumunda anlamlı farklılık gözlenmezken apikalde bu artefakt azalmaktadır. Cupping artefakt değerlendirildiğinde ise koronal ve apikalde artış görülmektedir. Bu durumun, streaking artefaktının görüntüde azalması ve cupping artefaktının daha görünür hale gelmesine bağlı olabileceğini düşünmekteyiz.

\section{SONUÇ}

Çalışmanın sonuçlarına göre kanal tedavisi uygulanmış dişlerde streaking artefaktı ve cupping artefaktı görülmektedir. Kök kanal dolgu patıyla ilişkili olarak en sık görülen artefakt streaking artefaktı olmuştur. Koronal ve apikal bölgelerde artefakt görülme frekansı ve yüzde dağılımları incelendiğinde apikal kısımda artefakt sayısı anlamlı ölçüde azdır.

Kök kanal dolgulu dişlerin KIBT ile değerlendirilmesinde streaking artefaktının azaltıması için, küçük FOV ve vokselde görüntüleme yapılması önerilmektedir.

Artefakt oluşumunun azaltılması konusunda kök kanal dolgusunda kullanılan materyallerin içerikleriyle ilgili ileri çalışmaların yapılması faydalı olacaktır.

\section{Teşekkür}

Bu çalışma Suileyman Demirel Üniversitesi Bilimsel Araştırma Projeleri Koordinasyon Birimi tarafından 4375-DU2-15 proje numarası ile desteklenmiştir. 


\section{KAYNAKLAR}

1. Kim HK. Evaluation of the repeatability and matching accuracy between two identical intraoral spectrophotometers: an in vivo and in vitro study. J Adv Prosthodont 2018;10:252-8.

2. Van der Burgt T, Ten Bosch J, Borsboom P, Kortsmit W. A comparison of new and conventional methods for quantification of tooth color. $J$ Prosthet Dent 1990;63:155-62.

3. Chu SJ, Trushkowsky RD, Paravina RD. Dental color matching instruments and systems. Review of clinical and research aspects. J Dent 2010;38 2-16.

4. Brewer JD, Wee A, Seghi R. Advances in color matching. Dent Clin North Am 2004;48:341-58.

5. Dagg H, O'connell B, Claffey N, Byrne D, Gorman C. The influence of some different factors on the accuracy of shade selection. J Oral Rehabil 2004;31:900-4.

6. Paul SJ, Peter A, Rodoni L, Pietrobon N. Conventional visual vs spectrophotometric shade taking for porcelainfused-to-metal crowns: a clinical comparison. J Prosthet Dent 2004;92:577.

7. International Organization for Standardization. ISO 57251. Accuracy (trueness and precision) of measurement methods and results - Part 1: General principles and definitions. Geneva: ISO; 1994. Available at: https://www.iso.org/obp/ ui/\#iso:std:iso:5725:-1:ed1:v1:en

8. Kim-Pusateri S, Brewer JD, Davis EL, Wee AG. Reliability and accuracy of four dental shade-matching devices. $J$ Prosthet Dent 2009;101:193-9.

9. Hammad IA. Intrarater repeatability of shade selections with two shade guides. J Prosthet Dent 2003;89:50-3.

10. Karaagaclioglu L, Terzioglu H, Yilmaz B, Yurdukoru B. In vivo and in vitro assessment of an intraoral dental colorimeter. J Prosthodont 2010;19:279-85.

11.Tsiliagkou A, Diamantopoulou S, Papazoglou E, Kakaboura A. Evaluation of reliability and validity of three dental colour-matching devices. Int $\mathrm{J}$ Esthet Dent 2016;11(1):2-16.

12. Klotz AL, Habibi Y, Corcodel N, Rammelsberg P, Hassel AJ, Zenthofer A. Laboratory and clinical reliability of two spectrophotometers. J Esthet Restor Dent. 2018:1-5.

13. Luo MR, Cui G, Rigg B. The development of the CIE 2000 colour-difference formula: CIEDE2000. Col Res Appl 2001;26:340-50.

14.Paravina RD, Ghinea R, Herrera LJ, Bona AD, Igiel C, Linninger $\mathrm{M}$ et al. Color difference thresholds in dentistry. J Esthet Restor Dent 2015;27 Suppl 1:S1-9.

15. Yuan JC-C, Brewer JD, Monaco Jr EA, Davis EL. Defining a natural tooth color space based on a 3-dimensional shade system. J Prosthet Dent 2007;98:110-9.

16. Öngül D, Şermet B, Balkaya MC. Visual and instrumental evaluation of color match ability of 2 shade guides on a ceramic system. J Prosthet Dent 2012;108:9-14.

17. Weyhrauch $M$, Igiel $C$, Pabst $A$, Wentaschek S, Scheller $\mathrm{H}$, Lehmann $\mathrm{K}$. Interdevice agreement of eight equivalent dental color measurement devices. Clin Oral Investig 2015;19:2309-18.
18. Llena C, Lozano E, Amengual J, Forner L. Reliability of two color selection devices in matching and measuring tooth color. J Contemp Dent Pract 2011;12:19-23.

19. Koo TK, Li MY. A guideline of selecting and reporting intraclass correlation coefficients for reliability research. J Chiropr Med 2016;15:155-63.

20.Lehmann KM, Igiel C, Schmidtmann I, Scheller H. Four color-measuring devices compared with a spectrophotometric reference system. J Dent 2010;38 Suppl 2:e65-70.

21. Yuan $\mathrm{K}$, Sun $\mathrm{X}$, Wang $\mathrm{F}$, Wang $\mathrm{H}$, Chen JH. In vitro and in vivo evaluations of three computer-aided shade matching instruments. Oper Dent 2012;37:219-27.

22. Hugo B, Witzel T, Klaiber B. Comparison of in vivo visual and computer-aided tooth shade determination. Clin Oral Investig 2005;9:244-50.

23. Lagouvardos PE, Fougia AG, Diamantopoulou SA, Polyzois GL. Repeatability and interdevice reliability of two portable color selection devices in matching and measuring tooth color. J Prosthet Dent 2009;101:40-5.

24.Karl Martin Lehmann, Alessandro Devigus, Christopher Igiel, Stefan Wentaschek, Mehdi Sattari Azar, Scheller H. Repeatability of colormeasuring devices. Eur J Esthet Dent 2011;6:42935.

Yazışma Adresi:

Ayşe AYDOĞMUŞ ERIKK

Özel Akademi

Ağız Ve Diş Sağlığı Polikliniği

Antalya, Türkiye

Tel : +90505824 2570

E Posta: dt.ayseaydogmus@gmail.com 